\title{
Da apresentação comercial ao termo de quitação: analisando agências de artefatos mediadores do processo projetual
}

\author{
From the business proposal to the discharge term: analysing agencies of mediating \\ artifacts throughout the design process
}

\author{
LESNOVSKI, Melissa; Mestre; Unisinos \\ melissal@unisinos.br \\ CAMPELO, Filipe; Doutor; Unisinos \\ fcampelo@unisinos.br \\ MEYER, Guilherme; Doutor; Unisinos \\ gcmeyer@unisinos.br
}

\begin{abstract}
Resumo
Este artigo revisita os achados de investigação anterior, identificando artefatos mediadores do processo projetual e analisando as agências que estes exercem sobre as dinâmicas, alianças e controvérsias existentes no projeto, com foco na proposta comercial como um boundary object que media e articula os interesses e relações de atores dentro e fora da organização de design. 0 percurso metodológico compreendeu a elaboração de um modelo analítico da jornada da proposta comercial ao longo do projeto, a partir de entrevistas com especialistas. Com base nos resultados obtidos, discutiu-se o papel dos artefatos mediadores enquanto boundary objects do processo projetual como negociadores das fronteiras de heterogeneidades, além de identificar as relações da proposta comercial com outros artefatos de agenciamento. Tais reflexões deram margem para enquadrar a venda de serviços de design como o início de um coletivo de objetos mediadores que agenciam as relações sociais ao longo do projeto.
\end{abstract}

Palavras Chave: teoria ator-rede; processos de design; boundary objects.

\begin{abstract}
The present paper reviews findings from a previous investigation, identifying artifacts that mediate the design process and analysing their agencies over dynamics, alliances and controversies throughout the project, with special focus on the design business proposal as a boundary object that mediates and articulates interests and relationships among actors both inside and outside of the design organization. Methodological procedures involved the elaboration of an analytical model of the business proposal journey throughout the project, based on interviews with specialists. Based on the findings, a discussion has evolved around mediating artifacts as boundary objects for the design process, negotiating boundaries amidst heterogeneities, besides identifying relations between the business proposal and other agency artifacts. These discussions lead to the framing of the design services selling process as the starting point of a collective of boundary objects that promote agency over the social relations throughout the project.
\end{abstract}

Keywords: actor-network theory; design processes; boundary objects. 


\section{Introdução}

Dentro do ambiente contemporâneo de negócios, o sucesso de uma organização tem sido relacionado, dentre outros fatores, à vantagem competitiva provida pela terceirização de atividades de design (MOZOTA, 2011), tanto no âmbito de polinização cruzada como fomento à inovação (VERGANTI, 2012), quanto no sentido de reduzir custos operacionais fixos (MOZOTA, 2011). O projeto de design desenvolvido por uma organização fornecedora para uma organização cliente do design se inicia a partir da elaboração e aprovação de uma proposta comercial. Comumente entendida como um artefato imprescindível, porém coadjuvante do processo criativo de design, a proposta seria vista como um mal necessário, um conjunto de dispositivos burocráticos que selaria o acordo entre duas organizações, mas que pouco contribuiria para influenciar os caminhos e decisões criativas. A pesquisa que deu origem a este artigo desafiou tal afirmação: experiências prévias dos autores no mercado de trabalho trouxeram evidências que insinuam existir uma conexão entre o que se vende e o que se executa, pois a precificação dos serviços seria realizada mediante uma estimativa do esforço a ser empreendido através de um escopo de trabalho. A chave para o controle da incerteza projetual repousaria sobre a definição, portanto, da solução a ser provida ao desafio do cliente.

Seria possível definir, com precisão, a solução a ser proposta ainda na etapa de elaboração da proposta comercial? Artefatos mediadores do processo de design, em essência, devem atender à resolução de um problema de design. Tal problema, contudo, é influenciado por fatores que o tornam avesso a abordagens lineares - o termo wicked problem traduz situações em que não há um consenso claro sobre a natureza do problema, cuja resolução envolve suposições e decisões sob condições de risco e incerteza (KOSKINEN, MÄKINEN, 2009). O problema de design seria, portanto, aberto, complexo, dinâmico e em rede (DORST, 2015). Artefatos projetuais criados para abordar um problema complexo e, não raro, em deslocamento, envolveriam necessariamente tentativas de enquadrar o problema e propor sua solução, ainda na etapa comercial. É possível, pois, que a própria confecção de uma proposta de serviços de design e de seus artefatos projetuais derivados conformaria um serviço de design em si, especificando artefatos, processos, distribuição do projeto no tempo e recursos para sua realização. Refletir sobre artefatos projetuais e as condições em que eles são gerados é refletir sobre como o design projeta a realização de suas atividades.

Se a elaboração da proposta comercial de serviços de design marca o início das relações entre as empresas cliente e fornecedora, entende-se que especial atenção deva ser empregada ao contexto em que ela é criada. O documento, composto por regras, limites, escopo e dotação orçamentária, impacta não apenas o início do processo de design, mas também toda a prestação dos serviços, pois é o plano referencial do trabalho a ser executado. $\mathrm{O}$ acordo comercial pode ser entendido, de forma simplificada, como uma espécie de design do projeto de design, em termos infraestruturais: um script que determina direcionamentos, atividades, esforços e limites para a prestação dos serviços. Embora essa proposição possa insinuar um caráter autoral e unidirecional, os achados desta pesquisa apontam para a direção contrária - a elaboração da proposta comercial de design teria caráter profundamente social (LESNOVSKI et al., 2017). 
Iniciada através de requisitos preliminares providos pelo cliente (HAUG, 2015), a proposta comercial de design é elaborada ao longo de um ciclo reflexivo entre as organizações, envolvendo indivíduos de áreas diversas (BUCCIARELLI, 2002), onde as definições de escopo são conjuntamente enquadradas e reenquadradas de acordo com limites constantemente negociados. A utilização dos artefatos projetuais enfrentaria uma série de barreiras para o entendimento mútuo e compartilhamento efetivo de informações, oriundas da diversidade de mentalidades, tradições processuais distintas e variabilidade de sentidos e artefatos atribuídos ao design (BUCCIARELLI, 1998; KLEINSMANN, VALKENBURG, 2008).

O caráter social da emergência de requisitos e do emaranhado de relações em que ela ocorre apontou a necessidade de lentes mais apropriadas para observar o social em meio a atores humanos e não-humanos. A perspectiva da Teoria Ator-Rede trouxe maior clareza a esta investigação não apenas para observar as traduções ocorridas em fóruns híbridos de humanos e não-humanos, mas também conduzindo a evidências de que não haveria design, apenas re-design (LATOUR, 2008): os artefatos criados carregariam ramificações de artefatos anteriores e estenderiam seus próprios tentáculos a criações futuras. Nesse sentido, o que precederia e o que sucederia a proposta comercial de design? Haveria algo mais nesses artefatos do que o que as informações projetuais que carregam podem revelar?

Essas indagações foram acolhidas por meio da perspectiva dos boundary objects, introduzida por Star e Griesemer (1989) e utilizada, nesta pesquisa, na interpretação da proposta comercial e dos artefatos relacionados a ela como articuladores de divergências e pontos de vista conflitantes no processo de design. Ao assumirmos que as propostas de serviços de design são compostas a partir das visões de indivíduos de mundos sociais diferentes, nascem as condições para que esta proposta possa ser considerada um boundary object: um tipo de arranjo que permite a diferentes grupos sociais trabalharem conjuntamente sem, necessariamente, haver consenso entre eles (STAR, 2010).

Este artigo apresenta o primeiro de dois movimentos de pesquisa de uma dissertação de mestrado que se propôs a analisar a proposta comercial de serviços de design pela perspectiva dos boundary objects (LESNOVSKI et al., 2017). O movimento investigativo aqui elaborado aborda a cartografia, a partir de relatos de informantes especialistas da indústria da comunicação digital, do contexto de artefatos, agenciamentos e relações projetuais entre empresas que compram e vendem serviços de elaboração de websites. Ou seja - mapeou-se a trajetória de composição da proposta comercial e seu deslocamento, traduzido em outros artefatos, ao longo do projeto. $\mathrm{O}$ movimento seguinte, a ser detalhado em artigo subsequente, aplicou o modelo aqui exposto em três estudos de caso, norteando os esforços de cartografia de controvérsias e arqueologia de artefatos projetuais. A jornada desta investigação trouxe reflexões que - acredita-se - poderão contribuir para a ressignificação da proposta comercial de design e demais artefatos mediadores como elementos determinantes e articuladores do processo de prestação de serviços. Diferente de outras abordagens que focam nas relações de trabalho entre as partes, o foco deste estudo recai sobre o artefato gerador do trabalho.

Poder-se-ia posicionar o curso desta investigação na intersecção entre os estudos de cultura de projeto e os estudos sociotécnicos - pois busca compreender como os mecanismos, práticas e estratégias de trabalho do design impactam nas soluções providas, na percepção da relevância de tais soluções e nas relações entre os diversos atores do processo de design. 


\section{Referenciais teóricos}

O percurso teórico referente a este artigo, fundado na pesquisa anterior mencionada, analisou referências em estudos sociotécnicos, em especial a Sociologia das Traduções e a perspectiva dos boundary objects, em busca de aporte teórico para compreender associações heterogêneas, agenciamentos e colaboração dentro de contextos de interesses divergentes.

A Teoria Ator-Rede (referida, doravante, como TAR neste documento), ou Sociologia das Traduções, trata as relações sociais, incluindo poder e organização, como efeitos de redes. Os artefatos não seriam apenas produtos de relações, mas também propulsores, mediadores e estabilizadores das mesmas (LAW, 1992). A TAR analisa o vir-a-ser de objetos, a forma como estes funcionam e como são capacitados a agir (YANEVA, 2009), o que torna essa perspectiva útil para analisar os processos de design, extraindo a multiplicidade de atores e ações envolvidas (TERREY, 2013) e abordando-o não como uma questão de fato, mas como uma questão de interesse (LATOUR, 2008). A TAR apresenta uma metodologia coerente de incorporação dos não-humanos nos relatos científicos, em uma tentativa de ruptura com a tradição filosófica que opõe objetos a sujeitos (SAYES, 2013).

Os princípios da TAR - agnosticismo, simetria generalizada e livre associação (CALLON, 1984) nortearam o olhar dos pesquisadores e as decisões metodológicas para investigar as traduções presentes nos processos projetuais, seja na forma de equivalência, deslocamento ou traição, como pontuam Callon (1984) e Law (1997). As traduções relativas a problematização, interessamento, engajamento e mobilização, como descritas por Callon (1984), guiaram a organização do pensamento e dos relatos ao longo dos eixos temporais projetuais, assim como o pensamento de Latour sobre a formação de grupos (2012) e criação de alianças em meio a negociações multilaterais (CALLON, 1984).

Esta investigação se propõe a seguir evidências das associações entre humanos e nãohumanos a partir de controvérsias mapeadas nas situações a serem estudadas. A cartografia de Latour é abordada em maior profundidade por Venturini como um conjunto de técnicas voltadas a explorar e visualizar questões, um exercício de desenvolver dispositivos para observar e descrever o debate social, especialmente o que envolve questões sociotécnicas (VENTURINI, 2010).

Proposta por Star e Griesemer (1989), a perspectiva dos boundary objects volta seu foco a objetos que mediam as negociações entre mundos sociais diferentes e interesses divergentes. A subestruturação da forma dos boundary objects permite aos membros de diferentes grupos ler diferentes significados particulares a suas necessidades a partir do mesmo material, uma maleabilidade possível porque o material permanece flexível (ou subestruturado) no uso em grupo e mais focado no uso localizado (HENDERSON 1991; STAR, GRIESEMER 1989). Henderson (1991) aborda desenhos de engenharia como "cola social", tanto entre indivíduos quanto entre grupos, facilitando a cognição distribuída no trabalho de design em equipe. É possível enxergarmos semelhanças com a situação da proposta comercial e seus artefatos derivados, dispositivos de alistamento de atores e recursos, estruturados de forma a permitir uma articulação dos interesses e visões de uma diversidade de atores nas organizações envolvidas.

A validade de um objeto enquanto boundary object em determinada fronteira parece estar relacionada à mediação entre este e os mundos sociais que devam ser associados na colaboração heterogênea. Carlile (2002) reflete sobre as características que uma ferramenta, método ou objeto devem possuir para mediar a resolução conjunta de problemas em diferentes tipos de 
fronteira: sintática, semântica ou pragmática. Em produção mais recente, Stompff e Smulders (2016) propõem uma categorização de boundary objects para representações do design, classificados em função da fidelidade, nível de abstração, preocupação preponderante e objetivo.

\section{Método}

O percurso metodológico da investigação inicial (LESNOVSKI et al., 2017) foi composto por dois movimentos. No primeiro, uma pesquisa exploratória percorreu a jornada de uma proposta comercial e de seus artefatos derivados, de sua criação ao encerramento do projeto, através de entrevistas com especialistas, buscando compor um modelo ideal de como esse percurso é realizado e que atores, interesses e desafios são característicos desse processo. No segundo, três estudos de caso foram relatados e constituem uma cartografia de controvérsias que perpassa e critica o modelo ideal composto na etapa anterior.

Figura 1 - Percurso metodológico da investigação anterior

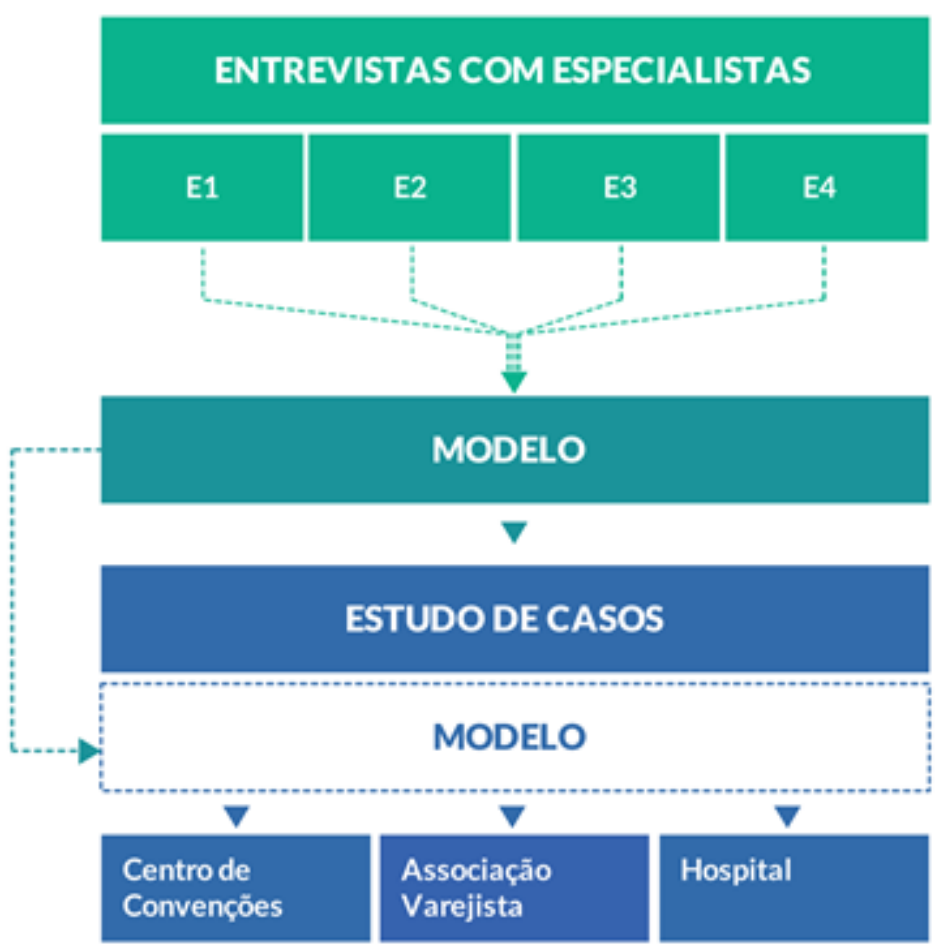

Fonte: LESNOVSKI et al., 2017

Este artigo foca seu olhar no primeiro movimento metodológico empreendido pela investigação inicial (LESNOVSKI et al., 2017) onde, em uma bateria de entrevistas em profundidade com quatro especialistas em comunicação digital do Rio Grande do Sul, foram providas informações para elaborar um modelo analítico da prática, confrontado posteriormente com três estudos de caso.

Os critérios para seleção dos especialistas abrangeram visão sistêmica e reflexiva sobre a 
venda e execução de serviços de criação de websites: os entrevistados detinham, individualmente, um mínimo de 10 anos de prática de mercado em comunicação digital, experiência na venda de serviços de design e participação no corpo diretivo da Associação Brasileira de Agentes Digitais, a ABRADi-RS. As entrevistas foram realizadas a partir de um roteiro referencial, que abordava questões essenciais para o esclarecimento da prática de composição, negociação e tramitação da proposta comercial de um website. As perguntas eram realizadas de forma conectada à narrativa do entrevistado, provocando aprofundamentos nas respostas e deixando-o livre para desenvolver seu relato.

Embora no início do processo de coleta houvesse a intenção dos autores de estabelecer categorias definidas para a análise de conteúdo, os relatos dos especialistas revelaram ênfase na sequência de fases, atores humanos e artefatos no processo projetual e influenciaram a opção por uma análise de conteúdo empírico-indutiva. Optou-se, pois, pela criação de um modelo do percurso da proposta comercial ao longo das fases do projeto, valendo-se da informação relativa às fases projetuais emergentes nos relatos. Dentro de cada categoria de fase projetual, foram localizados os artefatos e atores humanos de cada organização, assim como as traduções mais típicas manifestadas pelos especialistas.

\section{Apresentação de Resultados}

A partir da análise das entrevistas com especialistas, chegou-se a um modelo analítico, de caráter ideal, que foi, por sua vez, utilizado como base para a análise dos três estudos de caso apresentados na pesquisa original (LESNOVSKI et al., 2017).

\subsection{Prospecção}

Uma proposta comercial é produzida a partir de uma demanda de orçamento feita por um cliente a uma agência digital, originária de um conhecimento prévio entre as duas empresas, no qual a agência apresenta evidências, ao cliente, de que é suficientemente capacitada para atendêlo. Tais evidências podem ser apresentadas pela agência digital ao mercado de forma distribuída ou direcionada, na forma de visitas dos agentes comerciais da agência digital a um potencial cliente, denominado "prospect" (E1 , E3). A seleção das organizações a serem prospectadas são relacionadas a critérios definidos no plano comercial estratégico da agência digital (E1). A prospecção se inicia com a visita de um profissional de novos negócios da agência digital, muitas vezes denominado "hunter", a executivos da organização prospect, com o objetivo de apresentar a agência digital a esta, exibindo artefatos como portifólios e reels com os principais trabalhos já realizados pela agência (E3; E1).

\footnotetext{
"Se eu for encantar um cliente, é óbvio que eu vou preparar uma apresentação pré-venda, como um conceito, alguma coisa que ele precise tangibilizar, visualizar, antes de falar em negócio. Então o ideal é que nem se fale em dinheiro nessas situações. O ideal é ir lá e dar um show, tu não tá falando em escopo, não tá falando em dinheiro, em preço e condição de pagamento" (E1).
}

Esses artefatos trazem uma visão editada das características e feitos da agência digital, visando credenciá-la como capaz e digna de futuras solicitações de propostas de serviço por parte da empresa cliente.

“(...) monto um materialzinho direto pra lá. E aí a gente apresenta como é que funcionou o projeto do fulano. Como é que foi feito, a gente disseca o case e contextualiza aquele case pra necessidade do cliente. É um 'se vira nos 30'. (...) em alguns casos a gente acaba 
fazendo ferramentas auxiliares para a apresentação da proposta” (E3).

A escolha das empresas a serem prospectadas também obedece a uma lógica de conexão com relacionamentos anteriores. Agências que estabelecem relacionamentos profundos com segmentos específicos do mercado favorecem novas prospecções dentro desses mesmos segmentos, pois têm substancial vantagem competitiva frente a concorrentes (E3).

\subsection{Abertura da demanda e mapeamento de requisitos}

Segundo E2, a composição da proposta comercial se inicia com a demanda da empresa cliente à agência por uma descrição dos serviços e investimento necessários para elaboração de um dispositivo que venha a resolver determinado problema. $O$ ator que realiza essa solicitação, pelo lado da empresa cliente, normalmente é um analista de marketing (E1, E2), que pode tanto impulsionar quanto prejudicar a negociação (E1), embora não seja o decisor final. A compreensão desse profissional sobre comunicação digital constitui uma barreira para o avanço da composição da proposta, assim como o hiato de conhecimento de negócio entre o analista e seu gestor, que é o decisor. O mapeamento dos interesses do analista de marketing pode prover maior segurança no processo de elaboração da proposta comercial: o projeto não seria um fim em si, mas um instrumento para a projeção profissional do mesmo dentro da empresa (E1, E2).

"Na condição de funcionário, ele [o analista de marketing] defende, antes de mais nada, os interesses de preservação do próprio emprego, de crescimento dentro da empresa. Então ele procura apontar sucessos como parte da influência dele e falhas como problemas dos prestadores de serviço" (E2).

$\mathrm{Na}$ agência digital, o profissional que recebe o pedido de proposta está estabelecido na área comercial e é responsável por compreender a demanda do cliente e mapear seu processo de decisão (E1). A solicitação do analista de marketing requer que o agente comercial elabore uma proposta comercial para atender a determinado briefing, expresso ora no formato de uma lista de itens a serem executados, ora como um desafio proposto, a ser vencido (E2, E4). É interessante notar que esses pedidos - artefatos contendo inscrições dentro de um suporte legível (e-mails, arquivos PDF ou DOC), podem ser considerados boundary objects (STAR, 1989). A partir de suas estruturas, eles propiciam dinâmicas diferentes a partir de seus sentidos de fechamento (no caso da lista de itens) ou de abertura (no caso dos desafios) (STOMPFF, SMULDERS; 2016).

No primeiro caso, típico de empresas maiores, esse dispositivo se chama comumente RFP, do inglês request for proposal (pedido de proposta). Nesse documento, o analista detalha a solução ao desafio que enfrenta, solicitando a precificação dos serviços necessários (E2, E4).

\footnotetext{
“(...) você sabe que a RFP, mesmo a maior, tem esquisitices. Normalmente, os caras procuram modelos do que orçar no site, pegam o modelo do orçamento de uma empresa e mandam para outro fornecedor. Vêm umas RFPs que são uns monstrinhos, que não fazem sentido. Aí quando tu vai de fato fazer, tu vê que aquilo é um puta de um problema, porque tu orça banana, eles querem abacate. Foi inventar moda e não soube fazer" (E4).
}

No segundo caso, mais comum, o analista de marketing solicita à agência digital que proponha uma conformação de serviços que atenda a um desafio. Nesse caso, a agência deverá propor, ainda na etapa comercial, uma solução que atenda às dores relatadas pelo analista de marketing e detalhá-la suficientemente para que possa ser precificada (E2). Pode-se analisar a proposta comercial, nesse contexto, como um projeto do projeto de design, determinando estratégias, formatos, elementos e recursos para sua execução. 


\subsection{Elaboração da proposta}

O analista comercial, ao receber o pedido de proposta, aciona recursos humanos dentro da agência para interpretar o pedido do cliente e prever sua viabilidade, produzindo um artefato que descreva e consolide o acordo a ser proposto (E1; E2; E3). A análise do problema proposto pelo cliente normalmente é realizada por um profissional com experiência em planejamento de projetos digitais (E1; E2), em um contexto de coevolução do problema de design.

"Eu sempre coloquei isso [que construir uma proposta comercial de design já é projeto]. A tradução correta de design é projeto, e não desenho. Então a partir do momento que a pessoa te chama para conversar sobre uma ideia, trocar uma ideia e pensar numa proposta, os dois já estão projetando. Tanto cliente quanto agência já estão em processo criativo de elaboração" (E2).

O analista comercial recruta o profissional responsável pela área de produção para avaliar a quantidade de recursos necessários para a execução da mesma (E2). A precificação da proposta envolve a conversão dos recursos humanos e não-humanos previstos em moeda corrente, (E1), operação realizada através de colaboração sobre planilhas financeiras. A partir dos atores e competências listados acima, a proposta comercial é construída trazendo, em suas inscrições, os elementos de escopo, atores, aprovadores, provedores de insumos, preço, prazo e alinhamento de expectativas.

\subsection{Negociação}

Após elaborada, a proposta é apresentada ou entregue ao representante do cliente para que seja iniciado o ciclo de avaliação e negociação, sendo comum o replanejamento, ajuste e equalização da proposta comercial dentro desse processo (E2). Nesse momento, a proposta é um boundary object entre a equipe heterogênea com pessoas da empresa cliente e da agência digital.

\subsection{Contratação}

A contratação envolve a elaboração de documentos adicionais à proposta comercial, que acrescentam outros dispositivos para regular as relações entre as empresas além do escopo e investimento inicialmente propostos (E1).

\footnotetext{
"Quando aquele projeto é aprovado, aí a primeira coisa é geração de um contrato de serviço. Normalmente a gente tem um padrão de contrato de serviço. Normalmente tem uma discussão, que é conduzida pela pessoa comercial, e aí se estabelecem todas as decisões. Então o contrato também é um momento comercial“ (E3).
}

O contrato, portanto, também é objeto de discussão entre as equipes de cliente e agência digital, acionando atores até então não envolvidos no processo, como analistas jurídicos (E1). Ao contrato cabe dispor sobre os próprios mecanismos de modificação do projeto, uma vez que esteja em curso. A partir da consciência de que projetos de design mutam ao longo de seu desenvolvimento, o contrato carrega, dentro de si, dispositivos para a gestão de mudanças:

\footnotetext{
“As regras de gerenciamento de mudança devem estar lá, dentro do contrato. Mudanças para incluir, mudanças para excluir, transformar alguma coisa que já está no escopo. Então todas essas situações elas devem estar previstas em contrato, porque o que está em contrato não tem o que discutir, tu vai lá e aplica a regra e tá pronto" (E1).
} 
Se o contrato consiste em um boundary object para colaboração entre times heterogêneos, no andamento do projeto ele regula agenciamentos. Percebe-se a inevitabilidade da mutação de requisitos ao longo do projeto e a necessidade de dispositivos contratuais. A documentação do projeto à medida em que ele ocorre é citada como um meio eficaz para o controle da incerteza, consolidando decisões e protegendo a agência contra alterações de escopo (E2, E1).

\subsection{Kick-off}

Após a contratação, o projeto entra em execução, com ritos para a inscrição do mesmo dentro das plataformas e mecanismos de colaboração da empresa, em meio aos demais projetos e processos que fluem através das redes da agência. A identificação dos artefatos referenciais do projeto permite o acompanhamento da evolução dos serviços ao longo do projeto e o controle da incerteza (E1). Essa é uma reunião crítica, pois visa confrontar posições de risco:

\footnotetext{
"Muita gente não quer criar treta no kick-off. Quando eu digo que, se for pra fazer treta, cria no kick-off. Quer criar confusão, quer criar controvérsia, cria no kick-off. Porque ali dá tempo de evitar um desastre. Depois que tu não fez o kick-off, que o negócio entrou na esteira, aí já era, meu" (E1).
}

À medida em que o projeto entra em execução, profissionais de diferentes especialidades são envolvidos (E1) e os artefatos que fazem a mediação entre as equipes são ampliados e acumulados. Preservam-se os documentos da etapa de negócios e acrescentam-se novos artefatos (E2).

\subsection{Arquitetura de Informação}

Na etapa de Arquitetura da Informação, é estudada a distribuição das informações, fluxos e interações a serem realizadas pelos usuários no website. $O$ trabalho se inicia na análise do escopo do projeto e prossegue em rascunhos, wireframes e protótipos navegáveis (E1). O olhar sobre os rascunhos pode iluminar o estudo de momentos de intensa controvérsia dentro de um projeto, consistindo em artefatos que propiciem a abertura de perspectivas sobre o tema em elaboração (STOMPFF, SMULDERS, 2016). A baixa fidelidade dessa representação é um aliado para que se atenha a camadas mais essenciais do contexto analisado.

\subsection{Layout}

$\mathrm{Na}$ etapa de layout, são criadas interfaces com o branding da empresa cliente, seguindo as determinações da etapa de arquitetura de informação.

"A partir do momento em que se apresenta o layout, primeiro se estabelece uma discussão e insights "poderia ser diferente", "poderia ser assim". Existe sempre uma discussão sobre layout, sobre direção de arte. Porque ele é um artefato provocador. Isso é bom. Ele leva as pessoas a outros territórios" (E3).

A partir do layout, abrem-se perspectivas para novas reflexões entre os atores envolvidos, capazes de transportá-los a discussões ainda não exploradas.

“(...) eu vejo que o forum de discussão do projeto, todos os influenciadores, seja os atores diretamente atuantes no projeto, mas também quem paga, quem influencia, quem opina, o filho do cliente que vai olhar o layout e vai opinar em casa... tem diversos atores, dos mais bizarros... e é um grande jogo. (...) muitas vezes é pela própria insegurança de se está 
se fazendo um bom investimento, acaba querendo pegar opinião de pessoas de confiança, até mesmo familiares, por incrível que pareça. (...) Ou então o cliente ter algum problema de lembranças de infância em relação a certas cores e não querer que o layout remeta àquelas cores proibidas, quase como um trauma de palhaço" (E2).

Frente a dinâmica acima relatada, é possível refletir se o papel da agência digital, para mitigar esse tipo de influência, talvez envolvesse delimitar mais fortemente a rede projetual.

\title{
4.9 Desenvolvimento
}

Encenada por codificadores e desenvolvedores, a etapa de desenvolvimento faz uso de artefatos acumulados ao longo das etapas comercial e produtiva, além dos seus próprios.

\begin{abstract}
“Os artefatos vão sendo acumulados... preserva-se os documentos da etapa de negócios, com propostas que serão decupadas e aí começa a fazer um termo de abertura de projeto, com detalhamentos da parte tecnológica pra fazer especificação de requisitos, especificação funcional, diagramas, pra começar a passar isso pras equipes de desenvolvimento (...)" (E2).
\end{abstract}

O volume de artefatos produzidos para reflexão projetual varia de acordo com o porte e complexidade do projeto. Quanto mais funcionalidades e integrações com outros sistemas, maior a necessidade de criação de artefatos complementares (E2).

“E o raf não é só na parte de layout. Muitas vezes os diagramas de base de dados, toda essa parte vai ser rabiscada em quadros mesmo, em equipe, pra discutir em cima de diagramas, de pensar camadas de sistema..." (E2).

Os rafs, ou rascunhos, presentes em etapas anteriores de arquitetura da informação e layouts, também estão presentes na etapa de desenvolvimento, como objeto de discussão.

\subsection{Implementação}

Ao final da etapa de desenvolvimento, o projeto é testado em relação a suas funcionalidades e recebe a aprovação, pelo analista de marketing, para ir ao ar. Esse processo de implementação revela vários processos componentes e geradores de controvérsias, pois são gerenciados por equipes distintas e ordenados segundo interesses por vezes conflitantes (E1, E2).

\subsection{Finalização do projeto}

“E assim, fecha o ciclo formalmente. Assina lá o termo... e comemora. E aí pode emitir a última fatura" (E3).

A formalização da finalização do projeto é realizada através da confeç̧ão e assinatura de um termo de quitação, ou termo de aceitação do projeto (E2, E3, E1). Esse artefato textual delimita o marco final do processo projetual e ressignifica todas as demandas posteriores.

\subsection{Pós-venda}

O contexto pós-venda, também chamado de "manutenção", ou "manutenção evolutiva", é o conjunto de demandas relacionado a um contexto prévio, projetual, mas que conta com escopo e previsão orçamentária próprias (E3; E1).

\subsection{Modelo para estudo de casos}


A partir das contribuições dos entrevistados, o modelo (figura 2) possibilita a visualização das principais traduções ao longo do curso do projeto, conectadas a seus respectivos atores humanos e não-humanos, em específico os artefatos mediadores. O modelo se desenvolve ao longo de um eixo temporal, em que as diversas fases do projeto, pré e pós contratação, são alinhadas em sequência. Entende-se o percurso projetual como todo o arco delineado desde a prospecção até o pós-venda. Embora as lentes da TAR impliquem em assumir a simetria de grid de análise entre artefatos e humanos, o gráfico os apresenta de forma discriminada, para efeitos de clareza na compreensão da influência sucessiva entre os artefatos produzidos e dos humanos envolvidos em cada organização para cada tradução mapeada.

Figura 2 - Modelo analítico a partir dos relatos dos especialistas

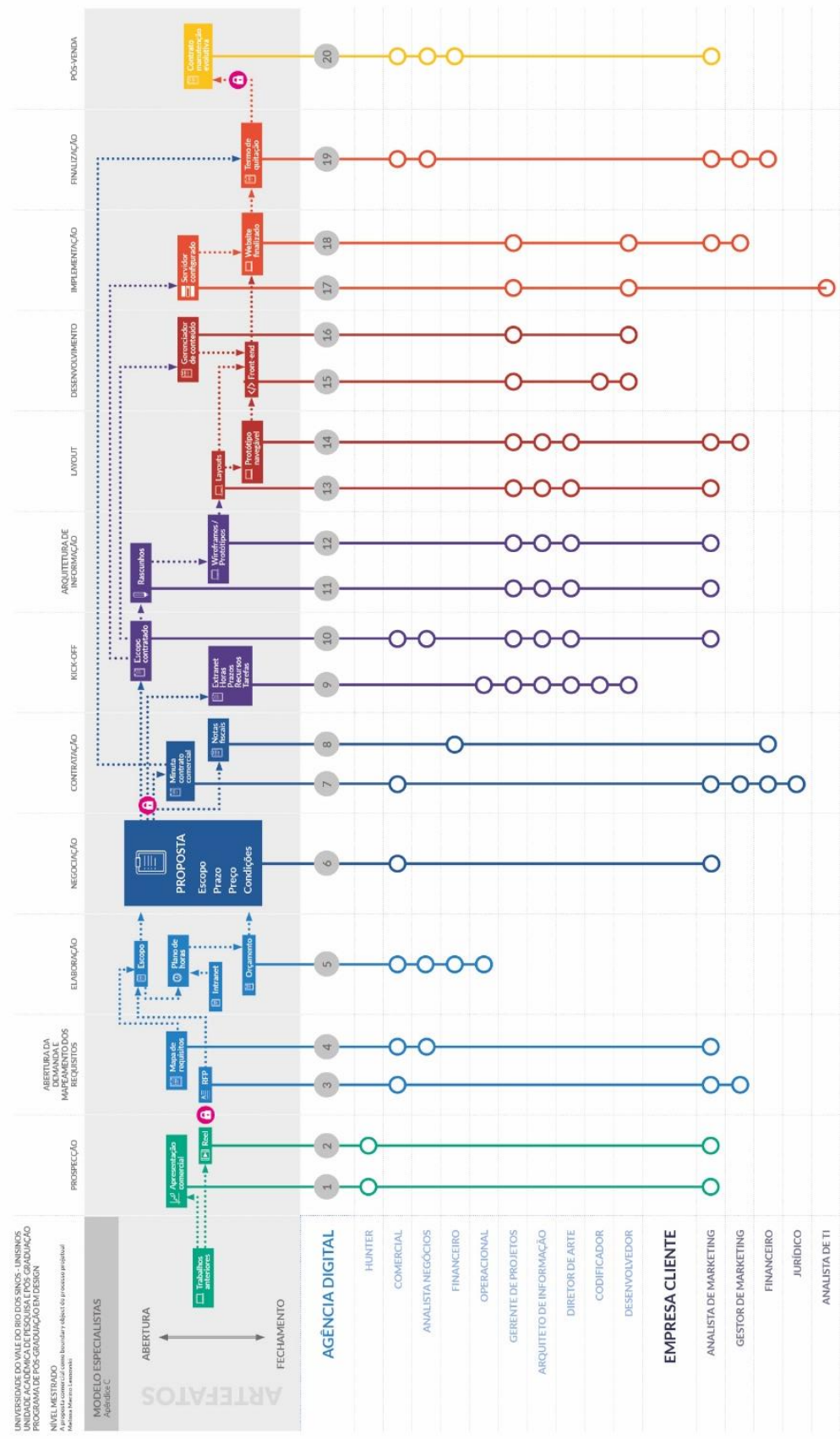

Fonte: LESNOVSKI et al., 2017 


\section{Discussão}

Os relatos coletados na pesquisa apontam que o ciclo de artefatos mediadores do processo de design é iniciado por um artefato de provocação inicial, de consistência e definição variável, sendo a proposta comercial composta a partir do levantamento de requisitos na organização cliente. A proposta, estruturadora do escopo do projeto e, em última instância, definidora dos limites de atuação do designer, é dependente de mapeamento das estruturas de poder e decisão da organização compradora. Nesse sentido, a Teoria Ator-Rede, mais precisamente a cartografia de controvérsias (VENTURINI, 2010; LATOUR, 2012), proveu substrato para discutir o mapeamento de questões sociais de maior complexidade.

A nova rede que a proposta descreve, na forma de escopo, se coloca a favor dos projetos de poder mapeados na organização cliente - sem esse alinhamento, a aprovação da proposta seria ameaçada. Nesse sentido, a proposta comercial é tanto um efeito de uma rede que compreende a empresa de design, a organização cliente e demais atores influenciadores no projeto em elaboração, quanto um instrumento de alistamento e um dispositivo de ativação de uma rede projetual a partir da contratação (CALLON, 1984, LATOUR, 2012, LESNOVSKI et al., 2017). Essa rede projetual tem parte de suas relações mediadas pela proposta - mais especificamente, por seus componentes internos e pelo coletivo de artefatos que é criado a partir desses componentes: rascunhos, wireframes, planos de trabalho, dentre outros. Ao mesmo tempo, a proposta é, ela própria, uma rede de instruções, limites, recursos e dispositivos de relacionamento, dignos de estudos mais aprofundados. A agência da proposta comercial no processo projetual, ao trazermos as lentes de Sayes (2013), é relacionada ao controle da estabilização do escopo e dos limites do objeto contratado; à mediação de relações em um coletivo, mutando e sendo mutada por ele; como membro do coletivo de artefatos estabilizadores de projetos de poder e agregadora de atores de diferentes ordens espaciais e temporais (LESNOVSKI et al., 2017). Nesse contexto, o termo "estabilização" é relativo: para a empresa cliente, a estabilização que se deseja é relativa a seu projeto de poder - a consecução dos objetivos estratégicos da organização e de seus representantes. Para a empresa vendedora, a estabilização envolve limitar o gasto de recursos (horas-homem) envolvidos no projeto. Como não há, necessariamente, sincronia entre os projetos de poder entre as organizações e entre seus próprios integrantes, o desafio que se apresenta para a proposta é lidar com uma realidade relacional complexa, em efervescência constante (LESNOVSKI et al., 2017).

Em uma análise geral sobre as traduções mediadas pela proposta comercial ao longo do projeto de design, pôde-se observar a formação de grupos em prol de alianças onde convergiam objetivos heterogêneos, envolvendo a problematização dos atores envolvidos, o estabelecimento de pontos de passagem obrigatória, elementos para o interessamento dos atores, dispositivos para seu engajamento e subsídios para que haja sua mobilização. Voltamos, pois, a um dos objetivos específicos desta dissertação, que é analisar a proposta comercial nas traduções ao longo do processo de design - um ciclo contínuo de leitura, ação, estabilização e desestabilização nas formações de grupos. Se a análise de tais traduções é possível por meio da cartografia das controvérsias do projeto, também se constata que a própria composição da proposta deriva de uma cartografia anterior, realizada não como uma investigação científica, mas como prática empírica.

As menções a imprevistos nos relatos dos especialistas, oriundos de elementos que não afloravam à superfície na ocasião do mapeamento da situação, insinuam que pode haver espaço 
para uma melhoria nos mecanismos de mapeamento das redes vigentes e dos múltiplos - e, às vezes, contraditórios - projetos de poder vigentes. Além do mapeamento, a definição dos pontos de passagem obrigatória para submissão dos atores da rede ao programa proposto (CALLON, 1984) parece ser essencial para a fixação da identidade dos atores e a formação de alianças que movam a rede formada em direção a seus objetivos conjuntos. Nesse sentido, a aceitação da instabilidade como parte do cenário pode conduzir à criação de soluções mais flexíveis e, potencialmente, mais propensas a prosperar envolvendo o reconhecimento dos projetos de poder vigentes e a negociação da articulação e mobilização de seus atores em prol dos objetivos específicos de cada um.

Tendo em vista o rol de artefatos e mediações disparados pela proposta comercial, cabe questionar o papel do agente comercial da empresa de design. Seria ele investido de novas capacidades para perceber, registrar e orquestrar relações, artefatos e humanos em constante recombinação (VENTURINI, 2010; LESNOVSKI et al., 2017). A articulação de redes de complexidades diferentes implica na habilidade do agente articulador em compreender as nuances da topografia de cada organização-rede: seus atores, projetos de poder, controvérsias. Essa compreensão, se lançarmos mão das reflexões de Latour (2012) e Venturini (2010), seria tão abrangente quanto mais o agente incorporasse as habilidades de um cartógrafo, percorrendo as evidências de controvérsias dentro das redes tangentes a seu trabalho. Os princípios da TAR, elaborados por Callon (1984), caberiam como condutores dessa cartografia: agnosticismo, simetria generalizada e livre associação. Uma análise que não faça juízo dos atores observados e de suas visões, que utilize o mesmo grid para questões técnicas e sociais e que abrace a livre associação de atores de qualquer natureza teria melhores condições de identificar os movimentos, contradições e projetos de poder no contexto em que se deseja, posteriormente, propor uma intervenção (LESNOVSKI et al., 2017). O vendedor-cartógrafo seria um provocador, ao mesmo tempo em que observa os efeitos de sua provocação nas redes que busca ativar. Como navegador privilegiado por sua posição fronteiriça às organizações, possa elaborar dispositivos que habilitem e empoderem os atores das organizações - em especial os que, por sua posição, têm maior vantagem, propensão e necessidade de formar alianças.

A partir da perspectiva de dispositivos - e das diversas agências inerentes a eles - o papel de negociação de fronteiras emerge como elemento estratégico da formação de alianças. A proposta comercial não é gerada de forma totalmente original, e sim é derivada de artefatos mediadores anteriores e conectada a outros artefatos mediadores paralelos a ela. Por sua vez, ela dá origem a artefatos que traduzem a proposta comercial no ordenamento das atividades projetuais. Sem eles, os dispositivos da proposta comercial não seriam levados a cabo e não haveria deslocamentos, transformações e traduções ao longo do projeto.

É possível, a partir dos relatos dos especialistas, imaginar - ou assumir - que a complexidade das relações projetuais é mediada por um boundary collective, um conjunto de boundary objects que desempenham mediações diferentes em cada contexto, regulando a abertura e fechamento de enquadramentos através de seus agenciamentos. A intencionalidade na criação de tais provocações, como rede, dependeria da consciência dos operadores sobre as capacidades desses artefatos em mediar relações, encenar provocações e deslocar o panorama projetual não apenas isoladamente, mas em rede. Assumir a elaboração do boundary collective como uma rede acoplável de artefatos mediadores implicaria em uma mudança substancial da cultura de aquisição de serviços de design: em vez de entregáveis, ou de um resultado, o que se 
comercializaria seria uma sequência de movimentos de tradução realizados por tais artefatos (LESNOVSKI et al., 2017). É possível que tal estratégia mitigasse a vulnerabilidade dos acordos comerciais reportada pelos especialistas, relacionada à impossibilidade de se prever desdobramentos que ocorrerão ao longo do projeto.

\section{Considerações finais}

Ressalvas feitas às limitações deste estudo, considera-se que esta pesquisa contribui para a ampliação de perspectivas sobre a proposta comercial como parte relevante do processo de design, frente às traduções que realiza. Da mesma forma, entende-se que este estudo pode iluminar a possibilidade de que o que entendemos, de forma pontualizada, como a proposta comercial consiste em um coletivo de artefatos cujas agências formam e dissolvem grupos, credenciam agentes, engajam atores e desenvolvem associações com projetos de poder dentro das organizações.

Investigações subsequentes poderão contribuir para amplificar e aprofundar esta pesquisa, expandindo-a para outros domínios do design - e verificando se os achados e reflexões aqui presentes são coerentes com outras realidades. Da mesma forma, poderão ser utilizadas abordagens metodológicas mais aprofundadas e adequadas a contextos sensíveis à revelação de informações críticas. Estudos futuros sobre controvérsias nos processos de design poderão representar avanços nas discussões sobre os agenciamentos encenados pelos artefatos mediadores. Olhares direcionados para as agências de outros boundary objects, como os briefs de design, por exemplo, podem trazer reflexões profundas sobre as articulações de redes envolvendo o enquadramento do problema de design.

\section{Referências}

BUCCIARELLI, Louis L. An ethnographic perspective on engineering design. Design Studies, v. 9, n. 3, p. 159-168, 1988.

BUCCIARELLI, Louis L. Between thought and object in engineering design. Design Studies, v. 23, n. 3, p. 219-231, 2002.

CALLON, Michel. Some elements of a sociology of translation: domestication of the scallops and the fishermen of St Brieuc Bay. The Sociological Review, v. 32, n. S1, p. 196-233, 1984.

CALLON, Michel. Society in the making: the study of technology as a tool for sociological analysis. The social construction of technological systems: New directions in the sociology and history of technology, p. 83-103, 1987.

CARLILE, Paul R. A pragmatic view of knowledge and boundaries: Boundary objects in new product development. Organization science, v. 13, n. 4, p. 442-455, 2002.

DORST, Kees. Frame innovation: Create new thinking by design. MIT Press, 2015.

DORST, Kees; CROSS, Nigel. Creativity in the design process: co-evolution of problem-solution. Design Studies, v. 22, n. 5, p. 425-437, 2001.

HAUG, Anders. Emergence patterns for client design requirements. Design Studies, v. 39, p. 4869, 2015.

HENDERSON, Kathryn. Flexible sketches and inflexible data bases: Visual communication, conscription devices, and boundary objects in design engineering. Science, technology \& human 
values, v. 16, n. 4, p. 448-473, 1991.

KLEINSMANN, Maaike; VALKENBURG, Rianne. Barriers and enablers for creating shared understanding in co-design projects. Design Studies, v. 29, n. 4, p. 369-386, 2008.

KOSKINEN, Kaj U.; MÄKINEN, Seppo. Role of boundary objects in negotiations of project contracts. International Journal of Project Management, v. 27, n. 1, p. 31-38, 2009.

LATOUR, Bruno. A cautious Prometheus? A few steps toward a philosophy of design (with special attention to Peter Sloterdijk). In: Proceedings of the 2008 annual international conference of the design history society. 2008. p. 2-10.

LATOUR, Bruno. Reagregando o social: uma introdução à teoria do ator-rede. Salvador: Edufba, 2012.

LAW, John. Notes on the theory of the actor-network: Ordering, strategy, and heterogeneity. Systems practice, v. 5, n. 4, p. 379-393, 1992.

LAW, J. Traduction/trahison: Notes on ANT. Department of Sociology and Social Anthropology, Keele University, Keele, England. 1997.

LESNOVSKI, Melissa; CAMPELO, Filipe; MEYER, Guilherme. A proposta comercial como boundary object no processo projetual. 2017.

MOZOTA, Brigite Borja de et. al. Gestão do Design. Porto Alegre: Bookman, 2011.

SAYES, Edwin. Actor-Network Theory and methodology: Just what does it mean to say that nonhumans have agency?. Social Studies of Science, v. 44, n. 1, p. 134-149, 2014.

SPEE, Andreas Paul; JARZABKOWSKI, Paula. Strategy tools as boundary objects. 2009.

STAR, Susan Leigh. This is not a boundary object: Reflections on the origin of a concept. Science, Technology \& Human Values, v. 35, n. 5, p. 601-617, 2010.

STAR, Susan Leigh; GRIESEMER, James R. Institutional ecology,translations' and boundary objects: Amateurs and professionals in Berkeley's Museum of Vertebrate Zoology, 1907-39. Social studies of science, v. 19, n. 3, p. 387-420, 1989.

STOMPFF, Guido; SMULDERS, F. E. H. M. The right fidelity: Designedly representations that enhance multidisciplinary product development. Design Management Institute, 2016.

TERREY, Nina. Managing by Design: Enacted Through Situated Networks. Design Management Journal, v. 8, n. 1, p. 52-61, 2013.

VENTURINI, Tommaso. Diving in magma: How to explore controversies with actor-network theory. Public understanding of science, v. 19, n. 3, p. 258-273, 2010.

VERGANTI, Roberto. Design-driven innovation: mudar as regras da competição: a inovação radical do significado de produtos. São Paulo: Canal Certo, 2012.

YANEVA, Albena. Making the social hold: Towards an actor-network theory of design. Design and Culture, v. 1, n. 3, p. 273-288, 2009. 